\title{
High Burden of Rheumatic Disease in Mexico: A Comprehensive Community-based Epidemiological Study
}

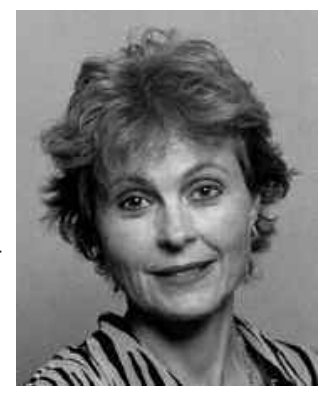

The current supplement to The Journal presents a series of articles on an excellent, well conducted, large epidemiological study of rheumatic disease in Mexico ${ }^{1,2,3,4,5,6,7}$. Various stakeholders participated in this endeavor, including professional associations such as the Colegio Mexicano de Reumatología, federal institutions, and private industry. The result is one of the largest community-based epidemiological studies including clinical evaluations specifically addressing the prevalence of musculoskeletal disorders. Five regions of Mexico were included: Chihuahua, Nuevo León, Sinaloa, Yucatán, and Mexico City. Over 19,000 individuals were evaluated using the methodology proposed by the Community Oriented Program for the Control of Rheumatic Diseases (COPCORD), a strategy used in various regions throughout the world in the past 3 decades $^{8}$. Briefly, the COPCORD method uses multistage random probability sampling to select participants, who are visited in their households by trained staff, and administered a survey. The Mexican version of the COPCORD questionnaire, previously used in a smaller study, was also used in this survey ${ }^{9}$. It includes questions about demographic and social characteristics, musculoskeletal pain, functional disability, self-reported conditions, and selected health behaviors. Participants who reported nontraumatic musculoskeletal pain $>1$ on a visual analog scale ranging from 0 to 10 , during the last 7 days or in the last 6 months, were clinically evaluated by a physician, and if a rheumatic disease was suspected, they were assessed further by a rheumatologist to confirm the diagnosis.

The use of the COPCORD strategy has clear strengths ${ }^{2}$. First, it is a well validated methodology to ascertain the prevalence of rheumatic disorders in the general population, with final case confirmation by rheumatologists; second, the method engages participation of community lay workers, which conceivably enhances participation rates; and third, it allows epidemiological comparisons to other regions in the world that have used this method.

The results of the study confirm the high burden imposed by rheumatic diseases in Mexico ${ }^{3}$, as has also been shown for other regions in the world ${ }^{10}$. Overall, 1 of every 4 individuals participating in the Mexican study reported nontraumatic musculoskeletal pain in the past 7 days $^{3}$. The preva- lence of other major rheumatic diseases varied across regions, but when all regions were considered together, osteoarthritis was diagnosed in $10.5 \%$ of respondents, rheumatoid arthritis in $1.6 \%$, ankylosing spondylitis in $0.1 \%$, and systemic lupus erythematosus in $0.06 \%$. Rheumatic regional pain syndromes were diagnosed in $3.8 \%$ of respondents. A note of caution: these overall frequencies cannot be equated to Mexican prevalence rates, or state rates, since the sampling was not weighted by regional population size or demographics, and included only 4 states and a major urban area, Mexico City. Nevertheless, the high frequency of musculoskeletal complaints across all regions highlights the substantial burden and healthcare needs in these large communities.

These data provide very important information for policy makers and health administrators in Mexico with respect to the significant burden of rheumatic disease. The prevalence of musculoskeletal pain was high, and most of the participants with pain had received drug therapy for this problem; many reported seeking care with a general practitioner. Further, in one of the predominantly rural regions, Yucatán, the prevalence of rheumatoid arthritis was $2.8 \%$, much higher than what has been reported in the United States, where the prevalence is below $1 \%{ }^{11}$. These findings support the need for adequate and comprehensive curriculums in rheumatic disease in medical school, residency training, and continuing medical education. Undergraduate medical education in Mexico varies greatly across universities, and in some schools is optional for medical students. Similarly, the need for a critical mass of rheumatologists is clear in view of the data reported here. Mexico has a population of 104 million, but only about 500 rheumatologists, clearly an insufficient number to provide adequate care for this large population, given the prevalence of rheumatic disease reported here. Moreover, 2 of the 31 states in Mexico do not have a practicing rheumatologist. Continuing medical education of rural primary care physicians is sparse, and particularly dismal with respect to rheumatology, creating inequalities in the provision of care for patients with rheumatic diseases in states without rheumatologists, and in rural areas. 
In addition to the public health and policy relevance of this study, the reported findings also provide important clues with respect to the epidemiology of these disorders across populations that differ in important socioeconomic, environmental, and cultural factors, and possibly other ethnic or genetic characteristics. Five regions were included in the survey. Mexico City and the state of Nuevo León are highly urban, $100 \%$ and $94 \%$, respectively, and had the highest rates of musculoskeletal pain (44\% and 23\%). The region with the lowest prevalence of pain was the most rural one, Sinaloa, with $7 \%$ of participants reporting pain. Fibromyalgia was also most frequently diagnosed in Mexico City $(1.7 \%)$ and least frequently in Sinaloa $(0.08 \%)$. These findings suggest a role for sociocultural factors related to urban life in the development and persistence of chronic pain. Of interest as well, the prevalence of rheumatoid arthritis was lowest in the highly urban regions, Mexico City (1\%) and Nuevo León $(0.7 \%)$, and similar to the prevalence reported in other regions in North America and Europe. In contrast, the prevalence of rheumatoid arthritis in Yucatán was 2.8\%, higher than in any of the other regions surveyed. Statistically significant differences in the prevalence of other disorders were also observed and are described in detail in the reports of the findings of the study.

In summary, the Mexican COPCORD study provides a much needed comprehensive report on the burden of rheumatic disease in this population, as well as fascinating findings showing marked variations across large geographic areas. While the reasons for these differences remain unclear, the observed variation provides an opportunity to further elucidate the effects of physical environment, social and cultural milieu, and genetics in the development and persistence of various rheumatic diseases.

MARIA E. SUAREZ-ALMAZOR, MD, $\mathrm{PhD}$, The University of Texas M.D. Anderson Cancer Center, 1515 Holcombe Boulevard, Unit 1465, Houston, Texas 77030, USA

Address correspondence to Dr. Suarez-Almazor;

E-mail:msalmazor@mdanderson.org

Dr. Suarez-Almazor has a K24 career award from the National Institute for Arthritis, Musculoskeletal and Skin Disorders (NIAMS grant AR053593) and is the Director of the Houston Center for Education and Research on Therapeutics funded by the Agency for Health Quality and Research (CERTs; U18 HS016093).

\section{REFERENCES}

1. Cardiel MH, Burgos-Vargas R. Towards elucidation of the epidemiology of the rheumatic diseases in Mexico. COPCORD studies in the community. J Rheumatol 2011;38 Suppl 86:1-2.

2. Goycochea-Robles M-V, Sanin LH, Moreno-Montoya J, Alvarez-Nemegyei J, Burgos-Vargas R, Garza-Elizondo M, et al; Grupo de Estudio Epidemiológico de Enfermedades Músculo Articulares (GEEMA). Validity of the COPCORD Core Questionnaire as a classification tool for rheumatic diseases. J Rheumatol 2011;38 Suppl 86:31-5.

3. Peláez-Ballestas I, Sanin LH, Moreno-Montoya J, Alvarez-Nemegyei J, Burgos-Vargas R, Garza-Elizondo M, et al; Grupo de Estudio Epidemiológico de Enfermedades Músculo Articulares (GEEMA). Epidemiology of the rheumatic diseases in Mexico. A study of 5 regions based on the COPCORD methodology. J Rheumatol 2011;38 Suppl 86:3-8.

4. Alvarez-Nemegyei J, Peláez-Ballestas I, Rodríguez-Amado J, Sanin LH, Garcia-Garcia C, Garza-Elizondo MA, et al. Prevalence of rheumatic regional pain syndromes in adults from Mexico: A community survey using COPCORD for screening and syndrome-specific diagnostic criteria. J Rheumatol 2011;38 Suppl 86:15-20.

5. Alvarez-Nemegyei J, Peláez-Ballestas I, Sanin LH, Cardiel MH, Ramirez-Angulo A, Goycochea-Robles M-V. Prevalence of musculoskeletal pain and rheumatic diseases in the southeastern region of Mexico. A COPCORD-based community survey. J Rheumatol 2011;38 Suppl 86:21-5.

6. Rodriguez-Amado J, Peláez-Ballestas I, Sanin LH, Esquivel-Valerio JA, Burgos-Vargas R, Pérez-Barbosa L, et al. Epidemiology of rheumatic diseases. A community-based study in urban and rural populations in the state of Nuevo León, Mexico. J Rheumatol 2011;38 Suppl 86:9-14.

7. Peláez-Ballestas I, Flores-Camacho R, Rodriguez-Amado J, Sanin LH, Esquivel-Valerio J, Navarro-Zarza E, et al. Prevalence of back pain in the community. A COPCORD-based study in the Mexican population. J Rheumatol 2011;38 Suppl 86:26-30.

8. Bennett K, Cardiel MH, Ferraz MB, Riedemann P, Goldsmith $\mathrm{CH}$, Tugwell P. Community screening for rheumatic disorder: cross cultural adaptation and screening characteristics of the COPCORD Core Questionnaire in Brazil, Chile, and Mexico. The PANLAR-COPCORD Working Group. Pan American League of Associations for Rheumatology. Community Oriented Programme for the Control of Rheumatic Disease. J Rheumatol 1997;24:160-8.

9. Cardiel MH, Rojas-Serrano J. Community based study to estimate prevalence, burden of illness and help seeking behavior in rheumatic diseases in Mexico City. A COPCORD study. Clin Exp Rheumatol 2002;20:617-24.

10. Brooks PM. The burden of musculoskeletal disease - a global perspective. Clin Rheumatol 2006;25:778-81.

11. Myasoedova E, Crowson CS, Kremers HM, Therneau TM, Gabriel SE. Is the incidence of rheumatoid arthritis rising?: Results from Olmsted County, Minnesota, 1955-2007. Arthritis Rheum; 62:1576-82. 